\title{
Predicting Technology Success: Identifying Key Predictors and Assessing Expert Evaluation for Advanced Technologies
}

Craig S. Galbraith ${ }^{1}$

Sanford B. Ehrlich ${ }^{2}$ Alex F. DeNoble ${ }^{2}$

\begin{abstract}
This study investigates a set of precursor factors that appear related to future technology success, and whether or not expert evaluators can a priori provide useful information during the technology review process. Sixty-nine highly advanced post 9-11 technologies are tracked over time. Based upon the results of this study, we conclude that a reasonably good predictive model can be constructed from organizational and technology factors, such as firm size, stage of development, and strategic partnerships. The results also indicate that the incremental value of expert reviewers and technology evaluators to predict future technology success is relatively small. Reviewers that provided the greatest predicative power, however, had current scientific responsibilities. These results raise important issues regarding the capability of developing predictive models of technology success.
\end{abstract}

Key Words: technology commercialization, prediction model, technology transfer

JEL Classification: $\mathrm{O} 32$

\section{Introduction}

Can we predict technology success? This is one of the most vexing, yet important questions in the field of technology commercialization. Almost every phase in the technology development process involves estimating the probability of successfully moving a technology ever closer to ultimate commercialization. Grant funding agencies constantly evaluate scientific proposals as to their technical merit hoping that their funded investigators will ultimately achieve a workable proof of concept.

\footnotetext{
${ }^{1}$ Cameron School of Business, University of North Carolina Wilmington, 601 South College Road, Wilmington, NC 28403 $U S A$

E-mail: galbraithc@uncw.edu

${ }^{2}$ College of Business Administration, Entrepreneurial Management Center, San Diego State University, Suite 1502, 5250 Campanile Drive, San Diego, CA 92182-1915, USA
}

University technology transfer offices and nascent research and development (R\&D) labs analyze the probability of obtaining future license agreements from internally generated inventions prior to investing in formal patent applications. Early stage angel investors evaluate whether or not a crude lab prototype will evolve into a successful field beta test, while later stage venture capitalists ultimately make hard predictions about the likelihood of future technology commercialization as part of their pre-deal due diligence.

Yet, in spite of the best efforts of everybody involved, it appears that predicting technology success is an elusive art at best. Most scientific efforts will never obtain intellectual property (IP) protection, most patents never produce a royalty check, most lab prototypes will be abandoned before they reach the field, and ultimately the majority of equity investments in technology ventures are total losses.

This study directly addresses this difficult problem of predicting technology success. Based upon a sample of highly advanced post 9-11 technologies, the study investigates a set of precursor factors that appear related to future technology success, and whether or not expert evaluators can a priori provide useful information during the technology review process. Sixty-nine technologies funded by the Center for Commercialization of Advanced Technologies (CCAT), a DoD/SPAWAR funded technology transfer agency, are tracked over time. All the technologies investigated in this study are of interest to the Departments of Defense and Homeland Security, and are considered in early to mid-stages of technology development, ranging from proof-of-concept to field prototyping. Unlike the vast majority of technology commercialization studies that take an ex post empirical perspective, 
this study captures the prediction data at the time of technology review, then tracks technology success over time.

\section{Literature review}

Interest in understanding the factors that lead to successful technology development and commercialization has been increasing exponentially during the last decade. Since Cooper's (1979) and Mardique and Zirger's (1984) seminal research, a number of subsequent studies have been published. At the present time, there appears to be a growing number of distinct, but overlapping, streams of scholarly work. For example, while government, university and corporate technology transfer experts often look toward the technology transfer literature, with scholarly outlets including the Journal of Technology Transfer, researchers examining the technology innovation process often follow $R \& D$ Management and the various innovation journals. The technology assessment literature, popular among public policy-makers and private think-tanks, is represented by journals such as the International Journal of Technology Assessment in Health Care and technical reports from various international agencies. Economists often study how new innovations develop and diffuse within society, reporting their findings in Research Policy, the Economics of Innovation and New Technology and other economic journals. Within the business disciplines, marketing experts have also had a long interest in new product development, and often important technology commercialization studies appear in the Journal of New Product Development. Finally, entrepreneurship scholars continue to examine a whole range of critical topics related to technology development, innovation, and technology commercialization as part of the entrepreneurial process. In fact, the majority of papers presented at the BabsonKaufman Entrepreneurship Research Conference, or published in the Journal of Business Venturing and Entrepreneurship: Theory and Practice now investigate some aspect of technology entrepreneurship, and how technology-based entrepreneurial firms develop successful strategies.

Across these diverse literatures some common research streams have appeared. One line of research examines the organizational process of developing and commercializing new products. Researchers have long argued that successful commercialization of innovative technologies typically involve a number of critical and observable steps (e.g., Dorf and Worthington, 1987; Galbraith et al., 1991; Cooper, 1993; Mock et al., 1993). In response, several highly structured, normative product development models have been proposed. These include the well-known Stage-Gate model (Cooper, 1993, 2001), the PACE process (McGrath, 1996), and a number of Stage-Gate variations that have a more technological orientation (Eldrid and Shaprio, 1996; Eldred and McGrath, 1997; Ajamian and Koen, 2002). Although the true benefit, and appropriate design, of such structured technology development processes is still largely unascertained, most large technology-based firms and government R\&D laboratories have now established some type of a formal technology review and funding support process (Ozer, 1999; Linton et al., 2002).

A second line of relevant research attempts to capture the critical factors that are positively correlated with successful new product innovation and commercialization. Taking this perspective, a large body of empirical "technology success" studies has developed over the past two decades (see MontoyaWeiss and Calatone, 1994; Balachandra and Friar, 1997; Griffin, 1997; Cooper, 2001; and Bellivea et al., 2002 for summaries). But while a number of empirical studies have investigated this issue, there appears to be little convergence regarding the number, definition, or underlying theoretical foundation of the key factors that contribute to successful technology commercialization (Balachandra and Friar, 1997; Astebro, 2004).

In spite of the lack of empirical agreement regarding the specific success variables, there does, however, seem to be some consensus regarding the classes, or groupings, of these key success factors. Astebro (2004), for example, suggests a general consensus around the dimensions of market, technology, environment, and organizational characteristics. Similarly, using a factor analytical procedure on 54 different variables, Heslop et al. (2001) group the key commercialization success variables into the four dimensions of market readiness, technology readiness, commercial readiness, and management readiness. 
Unfortunately, the vast majority of the efforts to examine technology development success in an ex post manner also suffer from various bias problems. These include hindsight or retrospective bias where successful innovators and entrepreneurs will create a contemporaneous impression of what led to a successful technology development, rather than remembering the actual sequence of confusing and non-obvious events (ChristensenSzalanski and Fobian 1991; Astebro 2004). Other common problems of ex post studies are survivor selection bias where only successful technology transfers are investigated or discussed (Elton et al., 1996; Shane and Stuart 2002), and memory decay where the technology developer simply can't remember the important decision points from the past (Carland et al., 1984; Davidsson and Honig, 2003).

Inevitably these biases result in fairly obvious factors, such as "having a superior product," "being aware of market demand," or "leveraging skills from a firm's core competence" being associated with successful technology development (e.g., Cooper, 2001). As such, this line of research has done little in providing early, a priori models of future technological success.

Given the lack of consensus regarding the underlying factors that contribute to technology success, some researchers, such as Balachandra and Friar (1997) and Galbraith et al. (2004) have suggested that there may not, in fact, be any "generic" success factors. There is increasing evidence that technology success factors must be tied to other aspects of the technology and organization, such as stage of review, nature of innovative activity, level of technology sophistication, and the structural/political nature of the market place.

But while much of the ex post technology commercialization research is somewhat tautological in nature (i.e., superior products have greater market success), this research has provided the foundation for developing various scoring systems for early technology review. In most structured approaches to technology development currently in practice, there is typically an early stage technology review process (Cooper, 1998; Ajamian and Koen, 2002), where a proposed technology is formally evaluated on criteria such as market attractiveness, future competitiveness, and technical merit. This is true whether the decision is a go/no-go internal corporate venturing decision, a government $R \& D$ review, or a Small Business Innovation Research (SBIR) grant funding exercise. Many of these early stage assessments now involve some type of multidimensional scoring sheet or rating process (Cooper et al., 2002). In fact, within the past decade there has been a stream of complex technology readiness check-lists or calibrated scoring models designed for early stage, or "fuzzy-front" end assessments (Mock et al., 1993; Koen et al., 2002). ${ }^{1}$ These include NewProd (Cooper, 1993) which incorporates a 30 item check-list and ProGrid (McCullough, 1998) which suggests nine dimensions of commercial readiness within a $3 \times 3$ grid. In addition, many large firms have developed their own, specialized early-stage assessment formats for internal use (Koen et al., 2002). A similar line of research has been undertaken within the university and government technology transfer community. Utilizing survey results from the university technology transfer officers, for example, Heslop et al. (2001) developed the multi-dimensional "cloverleaf" scale, while NASA has developed a series of technology commercialization assessment tools, such as those from the "Re-Invention Initiative Between Industry and Technology" (RIBIT) and "Long Evaluation and Analysis for Partnership" (LEAP) programs (Schoenborn and Fredette, 1997). An underlying assumption of all technology assessment check lists, however, is that individuals can accurately assess these characteristics in an a priori manner when evaluating an early-stage technology.

While tremendous effort has been placed on early-stage technology assessments, little is actually known about the predictive capability of these scales or whether the individuals that actually evaluate early-stage technologies have the insight, foresight, or skills to accurately assess the "technical merit" or "commercial potential" of such technologies. Perhaps there are organizational characteristics, such as investigator education or firm size that can also be used as a priori predictors of future technology development success.

Given these fundamental questions, and the hindsight and memory decay biases inherent in post hoc analysis, a few researchers are starting to examine technology commercialization or success within an a priori framework. For example, 
Astebro (2004) studied 561 R\&D "low-technology" Canadian projects evaluations from the mid1990s, and tracked their success over time. The research suggests that the factors of technology opportunity, developmental risk, expected profitability, and intellectual property protection provided the greatest explanatory power. Zacharakis and Meyer (2000) conducted a controlled experiment by providing a sample of experienced venture capitalists with different levels of information on 25 non-associated investments, and found that venture capitalists had at, best, a prediction accuracy of less than $40 \%$, and that this prediction accuracy decreased as more information was provided. By attempting to develop a statistical model of technology success from a priori information, our study falls within this more recent line of research.

\section{Method}

This research study examined 69 technologies funded by CCAT. CCAT is a congressional-funded consortium that has the specific mission of funding technologies being developed by small private sector $\mathrm{R} \& \mathrm{D}$ firms, government research agencies and university laboratories that have specific defense, homeland security, and anti-terrorism applications. In particular, proposals for funding are received and reviewed approximately three times per year. Between 2001 and 2003 approximately 600 proposals were received and reviewed by CCAT, and 69 were funded; thus, the present study only tracks the funded technologies. Around $70 \%$ of both the received and funded proposals are from small firms, with the remaining split between university and government laboratories. CCAT funding is considered supplemental (averaging around $\$ 75 \mathrm{k}$ ) to other funding sources, and many of the applicants have previously received SBIR and other DoD funding. The technologies are generally in early to middle stages of technology development, ranging between proofof-concept to lab prototype, with the CCAT funding specifically targeted to advancing the technology to the next phase of development. The technologies are classified as bio-chemical, software, communications, materials, electronics, energy, computers, biometrics, and sensors, and can all be considered highly advanced post 9-11 technologies. Examples of the technologies studied are "real time beryllium air particulate monitor," "new adjuvant class for enhancement of vaccinations," "specific multi-plex diagnostic test for West Nile Virus," "cross-language information extraction," "optical biosensors based on resonant structures on CCD-arrays," and "advanced gyroscopic infrared guidance systems." All of the technologies are considered to have dual-use capabilities for both government (e.g., military, homeland security) and commercial markets. Each received proposal is independently evaluated by a panel of experts, and scored, based upon the expert's assessments of reasonableness of request, technical merit, commercial potential, ability to sustain competitive advantage, and ability of the project team to execute the plan.

\section{Variables}

As a longitudinal study, we attempt to determine the predictive power of various organizational variables and expert assessments obtained at the time of the proposal submission, and how they relate to various objective and subjective measurements of technology success obtained one and a-half to three years later. In particular, the predictor variables were classified as "organizational variables" reflecting the characteristics of the firm, team, and technology, and "expert assessment variables" reflecting the individual expert assessments on five dimensions.

\section{Organizational variables}

The organizational variables were obtained from information provided in the proposal packet. These variables were coded as categorical variables and included: age of firm (AGE: 0-3 years, $3-5$ years, over 5 years), number of employees (EMP: 1-5; 6-20; 20-50; over 50), revenues (REV: none, less than $\$ 100 \mathrm{k}, \$ 100 \mathrm{k}$ to $\$ 500 \mathrm{k}, \$ 500 \mathrm{k}$ to $\$ 1 \mathrm{~m}$, over $\$ 1 \mathrm{~m})$, diversification level of firm (DIVER: single sector, related sectors, unrelated sectors), education of team (ED: highest level obtained by at least one team member, BA, Masters, Doctorate), stage of technology development (STAGE: concept, proof of concept, patent, lab prototype, field prototype, beta test, commercial), 
source of primary funding for the specific technology (SOURCE: self, private equity, government), total amount of external funding the specific technology has received to date from any source, such as government grants or equity investment (FUND: under $\$ 100 \mathrm{k}$, $\$ 100 \mathrm{k}$ to $\$ 750 \mathrm{k}$, over $\$ 750 \mathrm{k}$ ), and whether or not a previous formal strategic alliance or partner has been contracted with, such as an R\&D development agreement or a formal distribution agreement, that is specific to the technology under investigation (PART: no, yes). For the technologies developed in government or university laboratories, we coded AGE as the age of the technology within the lab. For size, we assumed that the lab had access to the advantages of large organizational size and overhead support (for example, a technology transfer office, attorneys, staff support, etc.); thus, EMP was coded as "over 50." For DIVER the various technologies being developed by the research team were analyzed, and in most, but not all, cases were recorded as a single sector activity. Since there was a somewhat subjective coding assessment for the government or university laboratory sub-sample, our research estimated models for both the full sample and the sub-sample of just private firms. Table I presents some summary statistics for the sample.

\section{Expert assessment variables}

Independent expert reviewers formally evaluated each received proposal on a number of dimensions defined by the CCAT review process. CCAT maintains a database of potential reviewers. All potential reviewers are queried based on their selfreported background areas of expertise, and then matched as reviewers for specific project categories. As typically in grant application reviewers are offered a small honorarium. Reviewers are then presented a number of applications in their area of stated expertise during a particular funding cycle. However, upon receiving the applications, if a reviewer feels that he or she is unable to accurately review a particular project, they are asked to not provide a review. Thus all expert assessment reviews in our analysis can be considered completed by a twice self-reported expert in the field (first, the original database self-reported background criteria and second, the opportunity to not complete a specific review).

Expert reviewers also provided a self-reported assessment of their current professional activity. The five categories of reviewer professional activity were venture capitalist/financer, engineer/scientist, administrator/program manager (also including technology transfer officer), entrepreneur, and consultant/service provider although all reviewers, regardless of professional background, had substantial experience with technology-based ventures. Each technology was evaluated by three to five reviewers. Approximately 70 different reviewers were used over the time period studied, resulting in approximately 180 total evaluations of the technologies under investigation.

We used five factors that were assessed by the expert reviewers: reasonableness of request,

Table I

Selected sample characteristics

\begin{tabular}{|c|c|}
\hline Variable & Sample size $=69$ \\
\hline $\begin{array}{l}\text { Technology } \\
\text { categories }\end{array}$ & $\begin{array}{l}\text { Bio-Chem }(27.5 \%) \text {, electronics }(21.7 \%) \text {; sensors }(17.4 \%) \text {, software }(17.4 \%) \text {, } \\
\text { communication }(8.7 \%) \text {, biometrics }(2.9 \%) \text {, materials }(1.4 \%) \text {, robotics }(1.4 \%)\end{array}$ \\
\hline Previous funding & Previous funding under $\$ 75 \mathrm{k}(40.0 \%)$; previous funding over $\$ 75 \mathrm{k}(60 \%)$ \\
\hline $\begin{array}{l}\text { Partnerships and } \\
\text { alliances }\end{array}$ & No formal alliances $(65.2 \%)$, formal alliances $(34.8 \%)$ \\
\hline $\begin{array}{l}\text { Number of } \\
\text { employees }\end{array}$ & $1-5(37.9 \%), 6-20(12.1 \%), 20-50(12.1 \%)$, over $50(37.9 \%)$ \\
\hline Highest degree & Bachelors $(10.3 \%)$, masters $(20.6 \%)$, doctorate $(69.1 \%)$ \\
\hline Diversification & Single technology $(59.5 \%)$, multi-technology $(40.5 \%)$ \\
\hline $\begin{array}{l}\text { Technology } \\
\text { development stage }\end{array}$ & $\begin{array}{l}\text { Concept }(4.3 \%) \text {, proof of concept }(17.4 \%) \text {, patent/patent application } \\
\text { filed }(18.8 \%) \text {, lab prototype }(39.1 \%) \text {, field prototype }(14.5 \%) \text {, beta-test }(5.8 \%)\end{array}$ \\
\hline
\end{tabular}


technical merit, commercial potential, ability to sustain competitive advantage, and ability of project team to execute plan, which directly correspond to the key dimensions reported by Heslop et al. (2001) and Astebro (2004). Reviewers used an 11-point Likert scale to score each variable.

\section{Success variables}

For the purposes of this study, the success of the technology was evaluated in late 2004, or approximately one and a half to 3 years after the initial evaluation. Technology success was measured in two ways. The first success metric (SUCCESS1) was an objective, market based measure of success, that is, whether or not a cooperative research and development agreement (CRADA) or license was signed, the technology received additional SBIR or equity funding, or an actual product was launched. SUCCESS1 was coded as bivariate $(0,1)$ variable. As a reference, of the 17 government laboratory technologies in the sample, 6 CRADAs formed and 3 licenses were signed. For the 10 university technologies in the sample, one advanced to the next level of funding. Of the 42 private firm technologies in the sample, 13 advanced to the next level of funding, 6 CRADAs were formed, 2 licenses were signed, and 5 commercial launches were undertaken. Since there was a possibility that some of the technologies had achieved other aspects of success not recorded above (e.g., still negotiating with a potential licensee but not formally signed) the senior CCAT/ SPAWAR project manager (not the authors of the study) was asked to assess each technology as a bivariate (not successful/successful) variable (SUCCESS2). He identified an additional three technologies that were "successes".

\section{Data analysis}

\section{Organizational model}

To determine an organizational prediction model of future technology success, various binary logistic regression models were estimated using the organizational variables as independent variables, and both SUCCESS1 and SUCCESS2 as the dependent variables. Two models were estimated: a pooled model incorporating both private firms and the university/government laboratories, and a model of just private firms. Several variables, such as revenues and source of funding, were ultimately dropped from the analysis due to both multicolinearity issues and lack of explanatory power when examined in preliminary model estimates.

\section{Expert assessment model}

As mentioned above, the detailed proposals are also reviewed by a panel of experts, with five items rated on an 11-point Likert scale. An "expert assessment" predictive model was thus estimated using the five items of expert evaluation of reasonableness of request, technological merit, competitive advantage, team ability, and commercialization potential as independent variables, and the success variables as the dependent variables. A pooled model of all reviewers combined is estimated, as well as, individual logistic regressions for each of the four professional backgrounds of the reviewers - scientist/engineers, administrators/ project managers, venture capitalists, and consultant/service providers. Due to insufficient sample size we did not analyze the "entrepreneur" reviewer sub-sample.

\section{Results and findings}

\section{Organizational model}

Table II provides the results for our final "organizational variable" model, a relatively parsimonious equation incorporating the seven explanatory variables of age of firm, number of employees, education level of technology team, diversification, total previous funding for technology, partnerships, and stage of technology development. Logistic regression results for both measures of success, SUCCESS1 and SUCCESS2 are reported in Table II.

Overall, the pooled models and the private-firm models produced relatively similar results. In the pooled model for SUCCESS2, all seven variables were statistically significant ( $p<0.10$, two-tailed), suggesting that smaller (negative coefficient on EMP) but established firms (positive coefficient on AGE), with a focused technology development strategy (negative coefficient on DIVER), in later stage of developments (positive coefficient on 
Table II

Technology success model: organizational factors - binary logistic regression

\begin{tabular}{|c|c|c|c|c|}
\hline \multirow[t]{2}{*}{ Organization variable } & \multicolumn{2}{|c|}{ SUCCESS1 } & \multicolumn{2}{|c|}{ SUCCESS2 } \\
\hline & Private sector model & Pooled model & Private sector model & Pooled model \\
\hline Constant & -4.100 & -4.797 & -4.611 & -5.080 \\
\hline $\mathrm{AGE}$ & $1.552 * *$ & $1.764 * * *$ & $1.216^{* *}$ & $1.464^{* *}$ \\
\hline EMP & -0.336 & $-0.481^{*}$ & -0.507 & $-0.600 *$ \\
\hline DIVER & $-0.929^{*}$ & $-0.936^{*}$ & $-0.797^{*}$ & $-0.732^{*}$ \\
\hline EDU & 0.438 & $0.722^{*}$ & 0.502 & $0.754 *$ \\
\hline STAGE & $0.918^{* *}$ & $0.990^{* * * *}$ & $0.837 * *$ & $0.911^{* * *}$ \\
\hline FUND & $-1.366^{* *}$ & $-1.438^{* * *}$ & $-1.448^{* *}$ & $-1.460^{* * *}$ \\
\hline PART & 0.738 & 0.553 & $1.968 * *$ & $1.393^{*}$ \\
\hline Nagelkerke $R^{2}$ & 0.403 & 0.471 & 0.439 & 0.490 \\
\hline$N$ & 42 & 69 & 42 & 69 \\
\hline
\end{tabular}

${ }^{*} p<0.10,{ }^{* *} p<0.05,{ }^{* * *} p<0.01$, two-tailed.

STAGE), receiving less total external funding for the technology (negative coefficient on FUND) have higher levels of future technology success. Education (high level of education for the research team) and formal partnerships were also statistically significant. Similar results were found for the pooled SUCCESS1 model except formal partnership was not statistically significant.

For the pooled model, the Nagelkerke $R^{2}$ was 0.471 (SUCCESS1 model) and 0.490 (SUCCESS2 model) suggesting a reasonably high goodness-offit. While the Nagelkerke $R^{2}$ in logistic regression is technically a "pseudo $R^{2 \text { " }}$ and does not reflect a "percentage of variance explained" as in OLS, it does provide a useful indicator of model fit when comparing different models. Similar results were obtained for the private firm model. With a Nagelkerke $R^{2}$ of 0.403 and 0.439 (SUCCESS1 and SUCCESS2 respectively), the private-firm model also appears to have a similar goodness-offit. Similar to the pooled model, AGE, DIVER, STAGE and FUND were statistically significant, with estimated coefficients in the same direction as the pooled model. However, EMP and EDU, while in the same direction as the pooled model, did not result in a statistically significant coefficient. PART was also statistically significant in the private-firm model using SUCCESS2. ${ }^{2}$

\section{Expert assessment model}

In order to examine whether or not expert reviewers provided some predictive power, a bin- ary logistic regression was analyzed using the five expert reviewer assessment factors as independent variables. Table III presents this analysis for the two success measures. In the pooled model of all reviewers, no significant results were obtained for SUCCESS2, and for the SUCCESS1 model only the "team ability" assessment variable was statistically significant, but in the opposite direction than expected. In addition, the Nagelkerke $R^{2}$ for the pooled models were only 0.036 (SUCCESS1) and 0.025 (SUCCESS2) indicating little or no predictive capability for the expert reviewers on the average.

In the specific professional background models, only one model (the scientist/engineer sub-sample) produced any significant results. Examining this sub-sample, we would perhaps naturally expect a more "accurate" assessment on the technical dimensions of the proposal, such as the "reasonableness of request" and "technical merit"-and, in fact, both of these variables were estimated in an expected direction with positive coefficients, although only the "reasonableness of request" was statistically significant. Interestingly the other statistically significant variable, "commercial potential" was opposite the expected direction. The Nagelkerke $R^{2} \mathrm{~s}$ of the scientist/engineer subsample models were a relatively high 0.257 and 0.307 for the two success measures respectively.

For the other three reviewer sub-samples (administrators/project managers, venture capitalists, and consultants/service providers), our analysis produced no statistically significant 
Table III

Technology success model: expert reviewer scores—binary logistic regression

\begin{tabular}{|c|c|c|c|c|c|}
\hline Evaluation criteria & All reviews & Scientist/engineer & $\mathrm{Admin} / \mathrm{mgr}$ & Venture capital & Conslt/provider \\
\hline \multicolumn{6}{|l|}{ SUCCESS1 models } \\
\hline Constant & -1.743 & -6.641 & -1.963 & -1.345 & -2.376 \\
\hline Reasonableness & 0.127 & $1.258 * *$ & -0.027 & 0.298 & 0.396 \\
\hline Technical merit & 0.063 & 0.067 & 0.396 & 0.232 & -0.353 \\
\hline Commercial potential & 0.100 & $-0.950 *$ & -0.036 & 0.279 & 0.113 \\
\hline Competitive advantage & -0.019 & 0.076 & -0.015 & -0.298 & -0.185 \\
\hline Team ability & $-0.233^{*}$ & 0.135 & -0.272 & -0.523 & 0.076 \\
\hline Nagelkerke $R^{2}$ & 0.036 & 0.257 & 0.065 & 0.099 & 0.117 \\
\hline$N$ & 180 & 37 & 71 & 27 & 30 \\
\hline \multicolumn{6}{|l|}{ SUCCESS 2 models } \\
\hline Constant & -1.358 & -6.782 & -1.016 & -0.784 & -2.932 \\
\hline Reasonableness & 0.070 & $1.408^{* *}$ & -0.099 & 0.380 & -0.079 \\
\hline Technical merit & -0.020 & 0.631 & 0.098 & -0.008 & 0.005 \\
\hline Commercial potential & 0.141 & $-1.024 * *$ & 0.039 & 0.375 & 0.342 \\
\hline Competitive advantage & -0.003 & -0.219 & -0.014 & -0.092 & -0.172 \\
\hline Team ability & -0.146 & -0.154 & -0.023 & -0.688 & 0.074 \\
\hline Nagelkerke $R^{2}$ & 0.025 & 0.307 & 0.014 & 0.133 & 0.073 \\
\hline$N$ & 180 & 37 & 71 & 27 & 30 \\
\hline
\end{tabular}

${ }^{* * *} p<0.01, * * p<0.05, * p<0.10$, two-tailed.

models, and the estimated models for these three sub-samples all had Nagelkerke $R^{2}$ s less than 0.140 . This suggests that these three groups of reviewers, when compared to perhaps the technical personnel sub-sample, are simply not very good at evaluating future technology success from the information available in this study.

\section{Combined organizational and expert evaluation model}

As a final analysis, we were interested in determining if the expert reviewers added any additional explanatory value above that provided by the organizational model. A fully specified model, including both organizational and expert reviewer assessment variables was then analyzed. A binary logistic regression model without the combined reviewer score was compared to the fully specified model with the combined reviewer scores added; statistically significant estimated coefficients on the reviewer scores were noted as were increases in the Nagelkerke $R^{2}$.

For the combined sample of all reviewers the addition of the combined expert reviewer scores increased the Nagelkerke $R^{2}$ by only 0.015 (SUCCESS1) and 0.017 (SUCCESS2) over the based organizational predictive model. In addition, in the fully specified model none of the expert reviewer factors were significant in the SUCCESS1 model, while in the SUCCESS2 model the one expert assessment variable that was statistically significant (competitive advantage) had a negative estimated coefficient-opposite from what would be expected. Other goodness-of-fit measures, such as the Cox and Snell $R^{2}$, log-liklihood, and percentage correct classification also indicated insignificant increases to model predictability when the expert reviewer scores were added to the base model.

Overall, again these results suggest that the incremental value of expert reviewers to predict future technology success beyond a basic organizational model for early to mid-stage technologies may be relatively small. ${ }^{3}$

\section{Bayesian data reduction analysis}

We performed a confirmatory-like analysis using the Bayesian Data Reduction Algorithm (BDRA). The results of the BDRA analysis were similar to that reported with the binary logistic regressions. For example, using the SUCCESS2 variable, The BDRA resulted in a parsimonious predictive model with the three organizational factors of 
EMP, DIVER and STAGE in a model that had a correct classification of $91.12 \%$. None of the expert assessment variables entered into the final BDRA predictive model. Appendix 1 provides more detail regarding the BDRA analysis.

\section{Conclusion}

Predicting the future successes of early to midstage technologies is one of the most fundamental of all technology management functions. Grant funding agencies, university technology transfer offices, corporate R\&D departments, nascent entrepreneurs, and venture capitalists all partake in this exercise. But, while we know, at least in hindsight, some of the factors that appear to be related to successful technological commercialization (e.g., a superior product), we know far less about the precursors to technology success and whether or not these factors can actually be predicted.

This study attempts to examine some of these issues. Using a sample of 69 early to mid-stage homeland defense technologies, we develop a predictive model of future technology success.

Several conclusions are suggested by the analysis. First, a reasonably good predictive model can be constructed from organizational factors; that is, the characteristics of the firm, the business model, the technology, and the research team. This finding somewhat parallels Roure and Keeley's (1990) argument that there is usually sufficient information in a written business plan to predict the success of a technology-based venture. Along that line, in our study, we found that sufficient information can be contained in a short "business plan-like" technology application to develop a statistically significant model of technology success.

From this analysis it appears that focused, small and more established firms/labs with midstage technologies (lab prototype or later) are associated with future technology successes. There is additional support that higher education levels of the research team and formal strategic alliances also contribute to future success. Our analysis also indicates that "leaner" might be better, with more fully funded technologies actually underperforming those with less early stage external funding.
Second, there is high consistency between our predictive logistic models and our models developed using the non-linear BDRA. This consistency provides a degree of confirmatory confidence to our analysis.

Third, on the average, expert reviewers provide little predictive value given the data in our study. The reviewers that appeared to provide the greatest predictive power, however, were those reviewers with current technical or scientific responsibilities. As a group, the expertise of venture capitalists, agency administrators, technology transfer officers, corporate and program managers, consultants, and service providers, added no statistically significant value to our predictive models.

While the results of our study are intriguing, there are also several limitations. First, because we studied only CCAT funded technologies, there may be a selection bias in the sample. Over 500 technology proposals were not funded by CCAT, and these were not included in the present sample. However, we believe that there is sufficient variation in both the reviewer evaluations and the organizational variables to reasonably examine the appropriate factors, and to move toward developing a predictive model of technology success. For example, each of the five reviewer assessment items had scores ranging between a low of 0 and a high of 10 , with variances ranging between a low of 3.71 and an high of 6.20 ; the organizational variables also ranged between the high and low points on each scale.

Second, although our analysis indicated, at best, only a marginal predictive ability by the expert reviewers, the reviewer scores in this study were based solely upon their reading of a lengthy proposal and summary of the firm, team members, target market, and technology. While in some situations this approaches actual reality (such as government grant reviews, large scale technology transfer office decisions, and preliminary venture capital business plan screenings), usually interested investors, consultants, and managers would ultimately get richer information through personal interviews and due diligence prior to a final assessment of a technology's chances.

In spite of these recognized limitations, we believe that our results raise important issues regarding the capability of developing predictive models, and the interplay between organizational 
factors and expert knowledge. In this spirit, we call for more aggressive empirical testing of the predictive capability of expert reviewers, technology "readiness" scoring models, and stage-gate type technology development programs.

\section{Notes}

1. Note that the use of technology assessments or readiness checklists in the context of predicting the future success of early stage technologies is different from "technology readiness levels" (TRL) which provide a structured means of measuring and communicating the maturity of technologies within acquisition programs, or assessing risk within complex technology based systems.

2. We also performed a similar binary regression using OLS. Because logistic regression is more appropriate with a binary dependent variable, the OLS results are not reported in this paper. However, for reference similar results were obtained with the OLS, with $R^{2}$ s in the range of $0.349-0.463$ for the organization variable base models. Similar results were also obtained with regard to the direction and statistical significance of the individual variables.

3. Due to sample size limitations and model convergence issues, individual logistic analyses of a fully specified model of the different reviewer sub-samples proved difficult, and thus are not reported.

\section{Appendix 1: Bayesian Data Reduction Algorithm (BDRA) results}

By their very nature linear methods, such as logistic regression and OLS, have a number of theoretical limitations particularly when attempting to develop predictive models from "fuzzy" input data. This has led to the development of a number of alternative classification and pattern recognition methods that relax many of the underlying assumptions inherent in linear methods. During the past decade, for example, particular interest has been paid to artificial neural network (ANN) paradigms (see Vellido et al., 1999; Zang, 2000 for good summaries). Several important neuro-classifiers have been developed, and the versatility of neural networks to provide powerful non-linear modeling capabilities without many of the assumptions of traditional linear classifications methods is well known. In spite of the potential power of ANN modeling, a number of limitations in ANN modeling are also evident (e.g., Hung et al., 2002). Another powerful classifier used in developing predictive models is the BDRA.
Developed by the U.S. Navy for advanced pattern detection and prediction, the BDRA is a classification method based upon the assumption that the discrete symbol probabilities of each class are a priori uniformly Dirichlet distributed (Lynch, 1999; 2003). The algorithm employs a modified backward sequential feature search process for reducing the irrelevant features from the training data of each class. BDRA differs significantly from neuro-classifiers by adjusting the data structure rather than focusing on obtaining the "best fit" model to the existing data. Unlike linear methods and neural networks, the BDRA does not necessarily remove whole features, but reduces the quantization complexity by removing discrete levels of the features, one at a time. The resulting model then provides a highly parsimonious classification scheme, with a minimum number of less complex predictor variables. In addition, model over-fitting appears to be substantially reduced with the BDRA (see Kline and Galbraith, 2004).

The BDRA is not to be considered a universally best classifier, but rather to provide superior performance when the "curse of dimensionality" is evident. Because of its focus on the data features and quantization, the BDRA is different from both "naive" Bayesian learning algorithms developed for neural networks training and Bayesian belief networks, and can be used to provide a confirmatory aspect to other classification methods, such as linear regression (Kline and Galbraith, 2004).

To provide a confirmatory analysis in this study, the BDRA was run on the full sample using the five items of expert assessment of reasonableness of request, technological merit, competitive advantage, team ability, and commercialization potential as predictor variables, and SUCCESS2 as the prediction variable. The BDRA was then run on the full sample using both the five items of expert evaluation and the seven organizational variables of age of firm, number of employees, education level of technology team, diversification, total previous funding for technology, partnerships, and stage of technology development as predictor variables. Because of the larger sample size requirements of the BDRA, the individual sub-samples of reviewer professional backgrounds could not be analyzed separately. Table IV provides the results of this analysis. 
Table IV

Technology success models: BDRA

\begin{tabular}{lll}
\hline Variable & Reviewer only limited model & Organization and reviewer full model \\
\hline AGE & - & NI \\
EMP & - & Bivariate $(-)$ \\
DIVER & - & Bivariate $(-)$ \\
EDU & - & NI \\
STAGE & - & Bivariate $(+)$ \\
FUND & - & NI \\
PART & - & NI \\
Reasonableness & Bivariate $(+)$ & NI \\
Technical merit & Bivariate $(-)$ & NI \\
Commercial potential & Bivariate $(+)$ & NI \\
Competitive advantage & Bivariate $(+)$ & NI \\
Team ability & Bivariate $(+)$ & NI \\
$\%$ Correct classification & $65.40 \%$ & $91.12 \%$ \\
\hline
\end{tabular}

$\mathrm{NI}=$ not significant when included in estimated model.

The five item expert evaluation BDRA model produced a prediction model with a correct classification of $65.40 \%$, a relatively low correct classification rate when building prediction models using either neuro-classifiers or the BDRA. As a point of reference regarding model prediction accuracy, a review of published research utilizing one of the most studied data based, the Wisconsin Breast Cancer data, suggests that depending on the techniques used, maximum classification performance for the test-sample ranges between $82.7 \%$ and $98 \%$. Although there is no formal statistical test for classification performance, in general, we consider a correct classification of over $80.0 \%$ to be a reasonable good model. In this model, the BDRA found all the variables useful in predicting future technology success.

However, in the full model incorporating both the five expert reviewer items and the seven organizational predictor variables, the BDRA produced a model with a correct classification of $91.12 \%$. In this model, the BDRA used only three variables (all reduced to a bivariate structure): number of employees (less than 10 employees), diversification (focused), and stage of development (lab prototype or higher). None of the expert reviewer items entered into the final BDRA model.

As a confirmatory model, the BDRA produced a model similar to our logistic regression models. In both the logistic regression and BDRA analyses, the stage of technology development and diversification were included in the predictive models. The BDRA also included number of employees, which in the logistic regressions were statistically significant in the pooled models. The other organizational factors in the logistic estimates were not used in the final BDRA models. Most importantly, however, was the consistent lack of incremental predictive power by the expert assessments in both the BDRA and regression analyses.

\section{References}

Ajamian, G. and P.A. Koen, 2002, 'Technology Stage Gate: A Structured Process for Managing High Risk, New Technology Projects,' in P. Belliveau, A. Griffin and S. Sorermeyer (eds.), PDMA Toolbook for New Product Development, New York: John Wiley and Sons, pp. 267295.

Astebro, T., 2004, 'Key Success Factors for Technological Entrepreneurs' R\&D Projects,' IEEE Transactions on Engineering Management 51 (3), 314-321.

Balachandra, R. and J. Friar, 1997, 'Factors for Success in R\&D Projects and New Product Innovation: A Contextual Framework,' IEEE Transactions on Engineering Management 44, 276-287.

P. Belliveau A. Griffin S. Somermeyer (eds.), 2002, The PDMA ToolBook for New Product Development, New York: John Wiley and Sons.

Carland, J., F. Hoy, W. Boulton and J. Carland, 1984, 'Differentiating Entrepreneurs from Small Business Owners: A Conceptualization,' Academy of Management Review 9, 354-359.

Christensen-Szalanski, J. and C. Fobian, 1991, 'The Hindsight Bias: A Meta-Analysis,' Organizational Behavior and Human Decision Processes 48, 147-168.

Cooper, R., 2001, Winning at New Products, Reading, MA: Perseus Publishing. 
Cooper, R., 1998, Product Leadership: Creating and Launching Superior New Products, Reading, MA: Perseus Publishing.

Cooper, R., 1993, Winning at New Products, 2 Redding, MA: Addison-Wesley.

Cooper, R., 1979, 'The Dimensions of Industrial New Product Success and Failure,' Journal of Marketing 43, 93-103.

Cooper, R., S. Edgett and E. Kleinschmidt, 2002, 'Optimizing the Stage-Gate Process: What Best Practice Companies Are Doing - Part I,'Research-Technology Management 45 (5), 21-27.

Davidsson, P. and B. Honig, 2003, 'The Role of Social and Human Capital Among Nascent Entrepreneurs,' Journal of Business Venturing 18, 301-331.

Dorf, R. and K. Worthington, 1987, 'Models of Commercialization of Technology from Universities and Research Laboratories,' Journal of Technology Transfer 12 (1), 1-8.

Eldred, E. and M. McGrath, 1997, 'Commercializing New Technology-II,' Research Technology Management 40 (2), 29-33.

Eldred, E. and A. Shapiro, 1996, 'Technology Management,' in M.E. McGrath (eds.), Setting the PACE in Product Development., Boston, MA: Butterworth and Heinemann, .

Elton, E., J. Martin and C. Blake, 1996, 'Survivorship Bias and Mutual Fund Performance,' Review of Financial Studies 9, 1097-1120.

Galbraith, C., A. DeNoble and S. Ehrlich, 2004, 'Spin-In Technology Transfer for Small R\&D Bio-Technology Firms: The Case of Bio-Defense,' Journal of Technology Transfer 29, 377-382.

Galbraith, C., G. Merrill and K. Campbell, 1991, 'The Vertical Transfer of Technology in the Navy R\&D Community,' Journal of High Technology Management Research 2, 15-33.

Griffin, A., 1997, 'Modeling and Measuring Product Development Cycle Time across Industries,' Journal of Engineering Technology Management 14, 1-24.

Heslop, L., E. McGregor and M. Griffith, 2001, 'Development of a Technology Readiness Assessment Measure: The Cloverleaf Model of Technology Transfer,' Journal of Technology Transfer 26, 369-384.

Hung, M., M. Shanker and M. Hu, 2002, 'Estimating Breast Cancer Risks using Neural Networks,' Journal of Operational Research Society 53, 222-231.

Kline, D., and C. Galbraith, 2004, Performance Analysis of the Bayesian Data Reduction Algorithm (BDRA) in Two Group Dependent Variable Data, Technical Report 04-01, San Diego, CA: Center for Commercialization of Advanced Technology.

Koen, P., G. Ajamian, S. Boyce, A. Clamen, E. Fisher, S. Fountoulakis, A. Johnson, P. Puri and R. Seibert, 2002, 'Fuzzy-Front End: Effective Methods, Tools and Techniques,' in P. Belliveau, A. Griffin and S. Sorermeyer (eds.),
PDMA Toolbook for New Product Development, New York: John Wiley and Sons, pp. 2-35.

Linton, J., S. Walsh and J. Morabito, 2002, 'Analysis, Ranking and Selection of R\&D Projects in a Portfolio,' $R \& D$ Management 32 (32), 139-148.

Lynch, R. and P. Willett, 1999, 'Performance Considerations for a Combined Information Classification Test using Dirichlet Priors,' IEEE Transactions on Signal Processing 47, 1711-1715.

Lynch, R. and P. Willett, 2003, 'Bayesian Classification and Feature Reduction Using Uniform Dirichlet Priors,' IEEE Transactions on Systems, Man, and Cybernetics 33 (3), 448464.

McCollough, R., 1998, 'The ProGrid System: A Customized Expert System for Evaluation of Intellectual Capital,' Proceedings of the Workshop on Evaluating Technology for Commercial Exploitation, Ottawa: Federal Partners for Technology Transfer.

McGrath, M., 1996, Setting the PACE in Product Development, Boston, MA: Butterworth-Heineman.

Maidique, M. and B. Zirger, 1984, 'A Study of the Success and Failure in Product Innovation: The Case of the U.S. Electronics Industry,' IEEE Transactions on Engineering Management 31, 192-203.

Mock, J., D. Kenkeremath and F. Janis, 1993, Moving R\&D to the Marketplace: A Guidebook for Technology Transfer Managers, Falls Church, VA: Technology Prospects Inc.

Montoya-Weiss, M. and R. Calantone, 1994, 'Determinants of New Product Performance: A Review and Meta-Analysis,' Journal of Product Innovation Management 11 (5), 397-417.

Ozer, M., 1999, 'A Survey of New Product Evaluation Models,' Journal of Product Innovation Management 16, 77-94.

Roure, J. and R. Keeley, 1990, 'Predictors of Success in New Technology Based Ventures,' Journal of Business Venturing 5, 201-220.

Shane, S. and T. Stuart, 2002, 'Organizational Endowments and the Performance of University Start-ups,' Management Science 48 (1), 154-170.

Schoenborn, T. and J. Fredette, 1997, So You Want to Set Up a Technology Evaluation Program?, Cherry Hill, NJ: Federal Laboratory Consortium.

Vellido, A., P. Lisboa and J. Vaughan, 1999, 'Neural Networks in Business: A Survey of Applications,' Expert Systems with Applications 17, 51-70.

Zacharakis, A. and G. Meyers, 2000, 'The Potential for Actuarial Decision Models: Can They Improve the Venture Capital Investment Decision?,' Journal of Business Venturing 15, 323-346.

Zhang, G., 2000, 'Neural Networks for Classification: A Survey,' IEEE Transactions on Systems, Man, and Cybernetics - Part C 30, 451-462. 